\title{
Kahramanmaraş Florasında Doğal Olarak Yayılış Gösteren Salvia pilifera, Salvia tomentosa ve Salvia palaestina'nın Uçucu Yağ ve Sabit Yağ Kompozisyonları
}

\author{
Osman GEDİK ${ }^{1 \mathrm{a}}$ Yusuf Ziya KOCABAŞ ${ }^{2 b}$ Orçun ÇINAR ${ }^{3 \mathrm{c}}$ \\ ${ }^{1}$ KSÜ Ziraat Fakültesi, Tarla Bitkileri Bölümü, Kahramanmaraş, TÜRKIYE \\ ${ }^{2}$ KSÜ, Türkoğlu MYO, Tıbbi ve Aromatik Bitkiler Bölümü, Kahramanmaraş, TÜRKIYE \\ ${ }^{3}$ Batı Akdeniz Tarımsal Araştırma Enstitüsü, Antalya, TÜRKIYE \\ ${ }^{a}$ https://orcid.org/0000-0002-4816-3154, ${ }^{b}$ https://orcid.org/0000-0003-2831-8910 \\ chttps://orcid.org/0000-0002-8356-384X
}

*Sorumlu yazar: ogedik@ksu.edu.tr

\section{Ö Z E T}

Adaçayı (Salvia spp.) türleri, farmakolojik etkileri güçlü terpenler ve fenolikler bașta olmak üzere pek çok sekonder metabolit içermelerinden dolayı tıbbi ve aromatik değerleri oldukça yüksektir. Bu çalışmada Kahramanmaraş ili florasında doğal olarak yayılış gösteren endemik Salvia pilifera Montbret \& Aucher ex Benth., Salvia tomentosa Mill., ve Salvia palaestina Benth., türlerinin herba kısımlarının uçucu ve sabit yağ bileşenleri belirlenmiştir. Çalışma Kahramanmaraş Sütçü İmam Üniversitesi Ziraat Fakültesi Tarla Bitkileri Bölümüne ait olan Tıbbi ve Aromatik Bitkiler laboratuvarında yürütülmüştür. Uçucu yağ bileşenleri ve yüzde oranları GC/MS cihazında belirlenmiştir. Araştırma sonuçlarına göre üç farklı Salvia türünde 46 farklı uçucu yağ bileşeni belirlenmiştir. Endemik olan S. pilifera türü 46 bileşenden 32'sini bulundurması ile en fazla bileşene sahip türdür. $\mathrm{Bu}$ türlere ait uçucu yağda başlıca bileşenler türlere göre değişiklik göstermiştir. $S$. pilifera'da başlıca bileşen $\% 20.43$ ile $\alpha$-thujone iken, $S$. tomentosa'da $\% 19.32$ ile $\alpha$-humulen ve $\% 18.14$ ile 13 -epi-manool, $S$. palaestina'da ise \%23.23 linalil asetat ve \%22.57 ile $\beta$-caryophyllene başlıca bileşenler olarak belirlenmiştir. İncelenen türlere ait sabit yağda 20 farklı bileşen belirlenmiş olup, $S$. tomentosa en yüksek bileşen sayısına sahip tür olmuştur. Başlıca sabit yă̆ asit bileşenleri türlere göre değişiklik göstermiştir. S. pilifera' da \%36.37 ile gama-linolenik asit, S. tomentosa'da \%18.83 ile cis-11,14- ekosadienoik asit ve $S$. palaestina'da \% 38.10 ile heneikosanoik asidin başlıca sabit yağ asidi bileşenleri olduğu tespit edilmiştir. S. pilifera ve $S$. tomentosa'da doymamış yağ oranı doymuş yağ oranından yüksek iken, $S$. palaestina'da doymuş yağ oranı doymamış yağ oranından çok daha yüksek bir orana sahip olduğu görülmüştür. S. pilifera $\alpha$-thujone bakımından diğer türlerden daha yüksek bir orana sahiptir.

\section{MA KA L E B İ L G ÍS İ}

\section{Araștırma Makalesi}

Geliş : 16.09.2021

Kabul: 30.11 .2021

Anahtar kelimeler: Salvia palaestina, Salvia pilifera, Salvia tomentosa, Sabit yağ, Uçucu yağ

\section{Essential Oil and Fixed Oil Compositions of Salvia pilifera, Salvia tomentosa and Salvia palaestina Naturally Distributed in Kahramanmaras Flora}

\section{A B S T R A C T}

Sage (Salvia spp.) species have very high medicinal and aromatic values because they contain many secondary metabolites, especially terpenes with strong pharmacological effects and phenolics. In this study, essential and fixed oil components of the herbage of the endemic Salvia pilifera Montbret \& Aucher ex Benth., Salvia tomentosa Mill., and Salvia palaestina Benth., naturally distributed in the flora of Kahramanmaraş province were determined. The study was carried out in the Medical and Aromatic Plants laboratory of Kahramanmaraş Sütçü İmam University, Faculty of Agriculture, Department of Field Crops. Essential oil components and percentages were determined in the GC/MS device. According to the results of the research, 46 different essential oil components were determined in three different Salvia species. The endemic S. pilifera species has the highest number of components with 32 out of 46 components. The main components of the essential oil of these species varied according to the species. In $S$. pilifera the main component is $\alpha$-thujone with $20.43 \%$, in $S$. tomentosa with $19.32 \% \alpha$-humulene and $18.14 \%$ with 13-epi-manool, in S. palaestina with $23.23 \%$ linalyle acetate and $22.57 \%$. $\beta$-caryophyllene was determined as the main components. 20 different components were determined in the fixed oil of the examined species, with $S$. tomentosa having the highest number of components. The main fixed fatty acid component varied according to the species. The main fixed fatty acid components were found to be gamma-linolenic acid (36.37\%) in S. pilifera, cis11,14-eicosadienoic acid (18.83\%) in S. tomentosa, and 38.10\% heneicosanoic acid in S. palaestina. S. pilifera and $S$. tomentosa have a higher ratio of unsaturated fat than saturated fat, while $S$. palaestina has a much higher ratio of saturated fat than unsaturated fat. S. pilifera has $\alpha$-higher rate of $\alpha$-thujone than other species.

\section{ART ICLE INFO}

Research article

Received: 16.09 .2021

Accepted: 30.11 .2021

Keywords:

Essential oil, fixed oil, Salvia palaestina, Salvia pilifera, Salvia tomentosa

To Cite: $\quad$ Gedik O, Kocabaş YZ, Çınar O 2021. Kahramanmaraş Florasında Doğal Olarak Yayılış Gösteren Salvia pilifera, Salvia tomentosa ve Salvia palaestina'nın Uçucu Yağ ve Sabit Yağ Kompozisyonları, MJAVL Sciences. 11 (2) 186-193. 


\section{GİRIȘ}

Lamiaceae kozmopolit bir familyadır (Heywood ve ark., 2007). Dünya üzerinde Akdeniz Bölgesi iklim koşullarında, ılıman ve tropikal bölgelerde steplerde yetişebilen yaklaşık 236-cins ve 7200 takson içerir (Cantino ve ark., 1992). Bu familya üyelerinin büyük kısmından uçucu yağ elde edilir ve bu türler farmakoloji ile parfümeri sanayinde kullanılmasının yanı sıra birçok tür de baharat olarak kullanılır (Ceylan, 1976; Kintzios, 2000). Lamiaceae familyasının en fazla tür sayısına sahip olan Salvia L. cinsi yaklaşık 1000'i bulan tür sayısı ile başlıca Kuzey ve Güney Yarım Küre'nin ılıman ve sıcak bölgeleri olan; Orta Amerika, Güneybatı ve Orta Asya'da yayılış gösterir (Duman ve Byfield, 2000; Walker ve Sytsma, 2007; Güner ve ark., 2012). Türkiye'de 99 takson ile temsil edilmekte olup bu türlerden 58'i endemiktir ve endemizm oranı \%58'dir (Anonim, 2012). Latince kelime anlamı sağlığı ifade eden Salvia türleri; otsu, çalı veya yarı çalı formunda tek yıllık veya çok yıllık bitkilerdir. Genellikle belirgin aromatik kokuya ve salgı tüylerine sahiplerdir. Çiçekleri beyaz, sarı, pembe, mavi veya mor renkli, iki dudaklıdır. Farklı habitatlarda ve yükseltilerde yayılış gösterir (Davis, 1982; Celep, 2010). Salvia cinsine ait birçok tür; yılan 1sırması, göz problemleri, kısırlık ve menstrual düzensizlik, enfeksiyon hastalıkları, epilepsi, zehirlenme, alzheimer hastalarındaki unutkanlık sorunlarına, bağırsak problemleri gibi rahatsızlıklara karşı halk arasında kullanılmaktadır (Sezik ve Ezer, 1983). Salvia türlerinin içerdiği aktif bileşenleri belirlemek üzere yapılan çok sayıda çalışma mevcuttur. İncelenen türlerin biyolojik aktivitelerinin; antimikrobiyal, antiviral, antioksidant, antitümör etkiye sahip olduğu ve özellikle sinirsel ve zihinsel problemlerin ve gastrointestenal hastalıkların tedavisinde etkili olduğu gözlenmiş ve birçok Salvia türünün uçucu yağları; gıda, ilaç, kozmetik ve parfümeri endüstrisinde yaygın olarak kullanılmaktadır (Pavlidou ve ark., 2004; Albayrak ve ark., 2008; Şenel ve ark., 2010; Exarchou ve ark., 2015; Sarrou ve ark., 2017). Dünya üzerinde adaçay1 60 farklı rahatsızlığın tedavisinde kullanılmaktadır (Orhan ve Şener, 2007). Salvia türleri gerek tıbbi gerekse de birçok türü baharat olarak kullanımlarından dolayı ekonomik önem taşır. Salvia türlerinin bazıları tıbbi değer taşımalarının yanı sıra güzel görünümlü çiçekleri nedeniyle bahçe ve parklarda dekoratif süs bitkileri olarak yetiştirilmektedir. Kelen ve Tepe (2008)'ye göre $S$. pilifera'nın uçucu yağ bileşenleri; $\alpha$-thujene $\% 36.1, \alpha$-pinene $\% 13.8,1,8$-cineole $\% 9.2$, linalool \%1.9, trans-thujone \%3.6, terpinen-4-ol \%3.2, myrcene $\% 2.2$, limonene $\% 1.4, \beta$-phellandrene $\% 1.5$, terpinen4-ol \%3.2 olarak, Kaya ve ark., (2017)'a göre $S$. pilifera'nın uçucu yağ bileşenleri; $\alpha$-pinene \%2.5, $\beta$-pinene \%24.9, myrcene $\% 9.0$, limonene $\% 1.2$, $\alpha$-copaene $\% 1.8, \beta$-caryophyllene $\% 5.0, \alpha$-humulene $\% 7.9$, germacrene D \%1.2, caryophyllene oxide \%1.4, Kürkçüoğlu ve ark., (2019)'a göre $S$. divaricata'da $\alpha$-pinene \%6.1, 1,8-cineole \%34.4, camphor \%3.8, linalool \%7.8, linalyl acetate $\% 10.3$, $\alpha$-terpineol $\% 1.9$, geranyl acetate $\% 2.5$, geraniol $\% 1.6, S$. eriophora'da $\alpha$-pinene $\% 0.3$, bornyl acetate $\% 1.4, \beta$-caryophyllene $\% 7.4, \alpha$-humulene $\% 1.6$, germacrene D \%1.0, $\beta$ bisabolene $\% 1.2$, palustrol $\% 2.2$, caryophyllene oxide $\% 13.2$, hexahydrofarnesyl acetone $\% 3.1$, spathulenol \%2.2, thymol \%1.7, chavicyl angelate \%8.2, pentacosane $\% 3.4$, phytol \%3.9, heptacosane $\% 8.9$ olarak, S. longipedicellata'da $\beta$-caryophyllene $\% 47.9$, pulegone $\% 1.3, \alpha$-humulene $\% 11.5$, bicyclogermacrene $\% 4.4$, caryophyllene oxide $\% 8.5, S$. pilifera'da $\alpha$-pinene $\% 9.4$, camphene $\% 1.5$, sabinene $\% 1.1$, myrcene $\% 5.3,1,8$-cineole $\% 3.4$, camphor $\% 1.5, \beta$ caryophyllene $\% 4.2$, borneol $\% 1.2, \beta$-bisabolene $\% 1.5$, caryophyllene oxide $\% 4.2$, spathulenol $\% 1.0$, $\beta$-bisabolol $\%$ 5.0, $\alpha$-eudesmol \%4.0 olarak belirtilmiştir. Ege ve Batı Akdeniz Bölgesi'nde herbal çay olarak fazla miktarda kullanılan ve çoğunlukla floradan toplanarak ihraç edilen Salvia türleri Salvia fruticosa Mill. (Anadolu adaçayı) ve Salvia tomentosa Mill. (Çalba) türleridir. Özellikle Salvia fruticosa Mill. (syn. Salvia triloba L.) Türkiye'de doğal olarak yetişen ticari değeri yüksek önemli bir adaçayı türüdür. Türkiye, dünyada adaçayının en fazla toplandığı ülkelerden birisidir. Ülkemizde doğadan en fazla toplanan ve ticarete arz edilen Anadolu adaçayı (Salvia fruticosa Mill.)'dır (Anonim, 2020). Tüik verilerine göre 2012 yılında adaçayı ekiliş alanları 54 dekar iken 2020 yılında 6.655 dekara, üretim miktarı ise 7 tondan 1.271 tona yükselmiştir (Tüik, 2021). Kahramanmaraş florasında S. pilifera dışında endemik olarak S. recognita Fisch. \& C.A.Mey., S. caespitosa Montbret \& Aucher ex Benth., S. haussknechtii Boiss., S. hypargeia Fisch. \& C.A.Mey. ve S. cilicica Boiss türleri doğal olarak yayılış göstermektedir (Davis, 1982). Thujone bileşeni, antimutajenik, antibakteriyel etki gösterir (Baydar, 2005). Bu çalışmada Kahramanmaraş ili florasında doğal olarak yayılış gösteren; endemik $S$. pilifera ile $S$. tomentosa ve $S$. palaestina türlerinin toprak üstü kısımlarının (herba) uçucu yağ ve sabit yağ bileşenlerinin belirlenmesi amaçlanmıştır.

\section{MATERYAL VE METOT}

\section{Çalışmaya konu olan türlerin genel özellikleri}

S. pilifera çok yıllıktır ve $80-90 \mathrm{~cm}$ boya ulaşabilir. Mayıs-Haziran aylarında mavi-pembe-beyaz çiçekler açar. Kireçtaşı kayalıkları, meşe çalılıklarında, makiliklerde ve 90-2000 m yüksekliklerde yetişmektedir. S. tomentosa çok yıllık bir tür olup, 90-100 cm boya ulaşabilir. Nisan-Ağustos aylarında leylak- pembe veya beyaz çiçekler açar. Kireçtaşlı yamaçlar, Pinus brutia Ten., ve Pinus nigra J.F. Arnold, ormanlarında, Quercus pubescens L., makisinde ve 90-2000 m yüksekliklerde yetişmektedir. Salvia palaestina çok yıllık, 30-60 cm boylu, mayıs-temmuz aylarında leylak-beyaz çiçekler açar. Kireçtaşlı yamaçlar, meşe çalılıklarında ve terkedilmiş tarla kenarlarında ve 300-1200 m yüksekliklerde yetişmektedir (Davis, 1982; Kahraman ve ark., 2012). Çalışmada kullanılan türlere ait bitki örnekleri çiçeklenme dönemi olan haziran ve temmuz aylarında 2020 yılında Kahramanmaraş ilinde aşağıda belirtilen doğal 
yetişme ortamlarından toplanarak herbaryum materyali haline getirilmiş ve KSÜ Türkoğlu MYO Herbaryumunda muhafaza edilmektedir.

Çizelge 1. Çalışılan bitki örneklerinin toplandı̆̆ı lokaliteler ve toplayıcı numarası

\begin{tabular}{lll}
\hline Takson & Lokalite & Toplayıcı No \\
\hline S. tomentosa & C6, Kahramanmaraş, KSÜ Kampüs alanı, Türkiye & YZK 2268 \\
S. palaestina & C6, Kahramanmaraş, Nurhak, Eskiköy mahallesi, Türkiye & YZK 1521 \\
S. pilifera & C6, Kahramanmaraş, Nurhak, Elif ova yaylası, Türkiye & YZK 2477 \\
\hline
\end{tabular}

Belirtilen lokalitelerden çiçeklenme döneminde (04.07.2020) toplanan bitki materyalleri oda sıcaklığında gölgede kurutularak analizler için muhafaza edilmiştir.

\section{Uçucu yağ izolasyonu ve bileşenlerinin belirlenmesi}

Çalışmada kullanılan bitkilerin; kurutulmuş herba kısımları öğütülerek su distilasyonu yöntemi ile üç saat boyunca Neo-clevenger cihazında uçucu yağları çıkarılmıştır. Uçucu yağ için 50 gram öğütülmüş numune örneği kullanılmıştır. Distilasyon sonucu elde edilen uçucu yağlar Batı Akdeniz Tarımsal Araştırma Enstitüsü_ (BATEM) laboratuvarında GC/MS cihazında analiz edilmiştir. Buna göre; elde edilen uçucu yağların bileşenlerini belirleyebilmek için uçucu yağlar 1:100 oranında hekzan ile seyreltilmiştir. Uçucu yağ bileşen analizi GC/GC-MS (Gaz kromatografisi (Agilent 7890A)-kütle detektör (Agilent 5975C)) cihazı ile kapiler kolon (HP InnowaxCapillary; $60.0 \mathrm{~m}$ x $0.25 \mathrm{~mm} \times 0.25 \mu \mathrm{m}$ ) kullanılarak yapılmıştır. Analizde taşıyıcı gaz olarak $0.8 \mathrm{~mL} / \mathrm{dk}$ akış hızına sahip helyum gazı kullanılmış, numuneler cihaza $1 \mu \mathrm{l}$ enjeksiyon hacminde 40:1 split oranı kullanılarak enjekte edilmiştir. Enjektör sisteminin sıcaklığ $250^{\circ} \mathrm{C}$ 'de sabit tutulmuş, kolon sicaklık program $160^{\circ} \mathrm{C}\left(10\right.$ dakika), $60^{\circ} \mathrm{C}$ 'den $220^{\circ} \mathrm{C}$ ye $4^{\circ} \mathrm{C} /$ dakika ve $220^{\circ} \mathrm{C}(10$ dakika) olacak şekilde programlanmıştır. Bu sıcaklık programı kullanıldığında toplam analiz süresi 60 dakika olarak gerçekleşmiştir. Kütle dedeksiyonu için tarama aralığı $(\mathrm{m} / \mathrm{z}) 35-450$ atomik kütle ünitesi ve elektron bombardımanı iyonizasyonu $70 \mathrm{eV}$ olarak uygulanmıştır. Uçucu yağ bileşenlerinin teşhisi yapılırken WILEY ve OIL ADAMS kütüphanelerinin sonuçları kullanılmıştır. Elde edilen bileşenlerin yüzde oranları FID dedektör kullanılarak, bileşenlerin teşhisi ise MS dedektör kullanılarak tespit edilmiştir (Uysal Bayar ve Çınar, 2020). İncelenen türlerin uçucu yağ bileşenlerine ait GC/MS kromatogramları Şekill de verilmiştir.

\section{Sabit yağ izolasyonu ve bileşenlerinin belirlenmesi}

Toprak üstü aksamları toplanarak kurutulan bitki materyalleri öğütülmüş ve her örnekten 15 gram paketlenerek sabit yağ işlemi için hazırlanmıştır. Hazırlanan materyallerin sabit yağlarının temini için soxhlet cihazında petrol eteri yardımı ile 6-8 saat süre içinde distilasyon işlemi yapılmıştır. Sabit yağ bileşenleri Üniversite-Sanayi-Kamu İşbirliği Geliştirme Uygulama ve Araştırma Merkezi (ÜSKIM) laboratuvarında belirlenmiştir. Sabit yağ bileşenleri belirlenmesi için ekstrakte edilen yağ numunelerinden $0,1 \mathrm{~g}$ yağ alınarak üzerine $1 \mathrm{ml} 2 \mathrm{~N}$ metanollü KOH çözeltisi ilave edilir, 2 dakika vortekslenir ve 15 dakika beklenir.

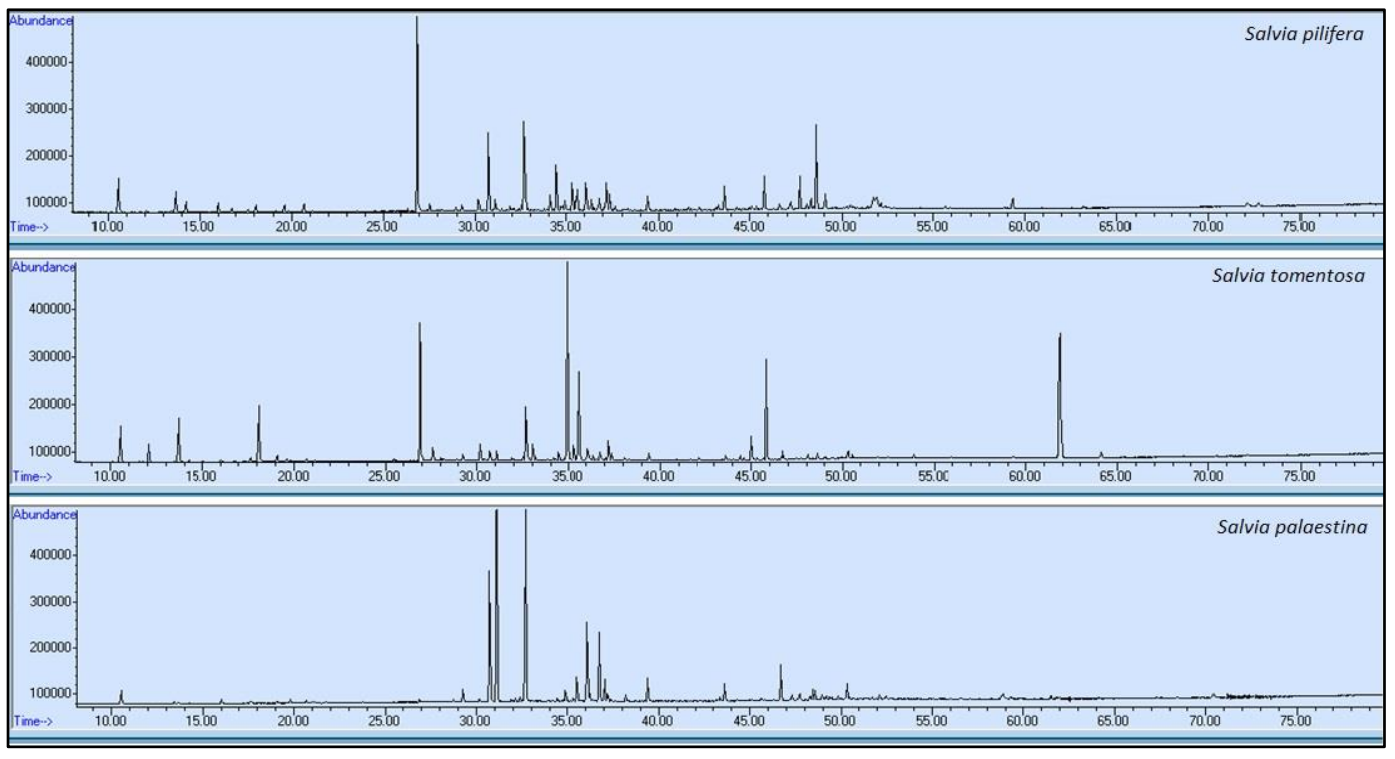


Şekil 1. İncelenen türlerin uçucu yağ bileşenlerine ait GC/MS kromatogramları



Şekil 2. İncelenen türlerin sabit yağ bileşenlerine ait GC/MS kromatogramları

Daha sonra üzerine $10 \mathrm{ml}$ hegzan ilave edilerek iyice karıştırılır faz ayrımı olması için 7000 rpm de 10 dakika santrifüj edilir ve üst fazdan 1 mikrolitre Shimadzu marka GC-FID cihazına enjeksiyon yapılır. Sabit yağ bileşenleri KSÜ ÜSKIM laboratuvarında belirlenmiştir. İncelenen türlerin sabit yağ bileşenlerine ait GC/MS kromatogramları Şekil 2 de verilmiştir.

\section{BULGULAR VE TARTIŞMA}

Bu çalışmada Kahramanmaraş florasında doğal olarak yayılış gösteren üç farklı Salvia türünün uçucu ve sabit yağ bileşenleri belirlenmiştir. Yapılan analiz sonucuna göre çalışılan bu türlerin uçucu yağlarında toplamda 46 farklı bileşik belirlenmiştir. Tablo 2'ye bakıldığında incelenen türlerden S. pilifera'da toplam 32 bileşen belirlenmiş ve bu bileşenlerin başlicası \%20.43 ile $\alpha$-thujone olup bunu \%10.87 ile $\beta$ - caryophyllene ve $\% 7.32$ ile $\alpha$ - bisabolol takip etmektedir. S. tomentosa türünde toplamda 23 farklı bileşen belirlenmiştir. Bunlardan \%19.32 ile başlica bileşen $\alpha$ humulene olmakla birlikte, \%18.14 ile 13-epi-manool, \%12.13 ile $\alpha$-thujone, \%8.21 ile borneol ve \%7.78 ile viridiflorol takip etmiştir. S. palaestina türünde toplam 21 adet bileşen belirlenmiş olup başlıca bileşen \%23.23 ile linalil asetat'tır. $\mathrm{Bu}$ bileşeni \%22.57 ile $\beta$-caryophyllene, \%12.77 ile linalool, \%8.96 ile germakren ve \%7.32 ile bicyclogermacrene izlemiştir. S. pilifera türünde alpha-terpineol (0.75), S. tomentosa türünde bicyclogermacrene (0.52) ve $S$. palaestina türünde beta-elemene'nin (0.41) en düşük orana sahip uçucu yağ bileşenleri oldukları belirlenmiştir (Tablo 2). Analiz sonucuna göre üç farklı Salvia türünde 20 farklı sabit yağ bileşeni belirlenmiştir. S.pilifera türünde başlıca sabit yağ asidi \%36.37 ile gama-linolenic asittir. Bu bileşeni \%18.07 ile palmitic acid, \%16.06 ile behenic acid, \%9.13 ile linoleic asit takip etmiştir. S. tomentosa türünde başlıca sabit yağ bileşeni \%18.83 ile Cis-11,14eicosadienoic asit, \%15.81 ile gama-linolenic asit, \%11.72 ile kapric acid, \%7.49 ile palmitic acid takip etmektedir. $S$. palaestina türünün başlıca sabit yağ bileşeni \%35.1 ile Heneicosanoic asittir. Bu bileşeni \%25.17 ile Capric acid, $\% 11.55$ ile y -linolenic acid, \%11.03 palmitic acid takip etmiştir (Tablo 3).

İncelenen türlere bakıldığında $S$. pilifera ve $S$. tomentosa türlerinde doymamış yağ oranı doymuş yağ oranından yüksek iken, S. palaestina türünde doymuş yağ oranı doymamış yağ oranından daha yüksek olduğu görülmüştür. S. pilifera 
türü ile yapılan çalışmalara bakıldığında; Kaya ve ark., (2017)'a göre S. pilifera türünün uçucu yağ bileşenlerinin başlıcası $\alpha$-pinene (\%24.9), myrcene (\%9), $\alpha$-humulene (\%7.9), Kürkçüoğlu ve ark., (2019)'a göre $\alpha$-pinene (\%9.4), borneol (\%1.2), caryophyllene oxide (\%4.2), $\beta$-bisabolol (\%5.0) olarak belirtilmiştir. S. tomentosa türü ile yapılan çalışmalara bakıldığında; Aşkun ve ark., (2010) yapmış olduğu çalışmada başlıca uçucu yağ bileşeni $\alpha$-pinene (\%25.1) olarak, kafur (\%14.9), borneol (\%13.2), $\alpha$-humulene (\%2.3), viridiflorol (\%1.8), Avc1 (2013), $\alpha$-pinene (\%24.65), borneol (\%29.32), trans-caryophyllene (\%6.74), 1,8-cineole (\%6.16), $\alpha$-terpineole/fenchyl alcahol (\%4.65) olarak belirtilmiştir. S. palaestina türü ile yapılan çalışmalara bakıldığında; Senatore ve ark., (2005)'a göre uçucu yağ bileşenlerini sclareol (\%20.2), $\beta$-caryophyllene (\%16.6), linalool (\%8.6), germacrene (\%7.2), caryophyllene oxide (\%3.8), Gürsoy ve ark., (2012)'a göre $\alpha$-thujene (0.9), $\alpha$-pinene (\%1.6), p-cymene (\%1.2), borneol (\%1.0), Al-jaber ve ark., (2012) 'a göre linalool Türkiye orijinlide \%2.1, İan orijinlide \%0.4 iken Lübnan orijinlide \%8.6 olarak, $\alpha$ copaene Türkiye orijinlide $\% 4.5$, İran orijinlide $\% 1.3$ iken iken, Lübnan orijinlide \%4.3 olarak, $\beta$-caryophyllene Türkiye orijinlide $\% 31.6$, İran orijinlide $\% 6.1$ iken Lübnan orijinlide $\% 16.6$ olarak, germacrene D Türkiye orijinlide $\% 20.9$, İran orijinlide \%14.0 iken, Lübnan orijinlide \%7.2 olarak, bicyclogermacrene Türkiye orijinlide \%10.8, İran orijinlide belirlenmezken, Lübnan orijinlide \%3.9 olarak, spathulenol Türkiye orijinlide \%9.5, İran orijinlide \%1.6 iken, Lübnan orijinlide \%3.4 olarak belirlenmiştir. Literatürde belirtilen bileşenlere ait değerler arasında bu çalışmadaki değerlerden düşük, benzer ve yüksek olanlar yer almaktadır.

Çizelge 2. S. pilifera, S. tomentosa, ve S. palaestina'nın uçucu yağ bileşenleri

\begin{tabular}{|c|c|c|c|c|}
\hline \multirow{2}{*}{ RI } & \multirow{2}{*}{ Bileşen Adı } & \multicolumn{3}{|c|}{ Bileșen Oranı (\%) } \\
\hline & & S. pilifera & S. tomentosa & S. palaestina \\
\hline 1021 & $\alpha$-pinene & 3.37 & 3.13 & 1.56 \\
\hline 1063 & Camphene & - & 1.70 & - \\
\hline 1106 & $\beta$-pinene & 2.33 & 4.33 & - \\
\hline 1119 & Sabinene & 1.17 & - & - \\
\hline 1160 & $\beta$-myrcene & 0.94 & - & - \\
\hline 1208 & 1,8 -cineole & 0.87 & 5.42 & - \\
\hline 1243 & $\mathrm{\gamma}$-terpinene & 0.80 & - & - \\
\hline 1268 & Cymene & 0.89 & - & - \\
\hline 1427 & $\alpha$-thujone & 20.43 & 12.13 & - \\
\hline 1446 & $\beta$-thujone & 0.89 & 1.21 & - \\
\hline 1495 & $\alpha$-copaene & - & - & 1.30 \\
\hline 1523 & $\beta$-bourbonene & 1.42 & 1.80 & - \\
\hline 1540 & Linalool & 6.66 & 0.76 & 12.77 \\
\hline 1552 & Linalyl acetate & 0.86 & 0.66 & 23.23 \\
\hline 1592 & $\beta$-elemene & - & - & 0.41 \\
\hline 1603 & $\beta$-caryophyllene & 10.87 & 4.85 & 22.57 \\
\hline 1615 & Aromadendrene & - & 1.32 & - \\
\hline 1651 & Sabinyl acetate & 1.40 & - & - \\
\hline 1662 & Trans- $\beta$-farnesene & 3.93 & 0.58 & - \\
\hline 1677 & $\alpha$-humulene & 1.15 & 19.32 & 1.08 \\
\hline 1692 & $\beta$-fenchyl alcohol & 2.80 & 1.27 & - \\
\hline 1698 & $\alpha$-terpineol & 0.75 & - & 2.35 \\
\hline 1701 & Borneol & 2.30 & 8.21 & - \\
\hline 1718 & Germacrene & 3.37 & 1.16 & 8.96 \\
\hline 1723 & Neryl acetate & - & - & 1.04 \\
\hline 1729 & $\alpha$-muurolene & 1.05 & - & - \\
\hline 1742 & Bicyclogermacrene & - & 0.52 & 7.32 \\
\hline 1745 & Piperitone & 1.55 & - & - \\
\hline 1753 & Geranyl acetate & - & - & 1.86 \\
\hline 1759 & $\Delta$-cadinene & 3.50 & 1.52 & 0.81 \\
\hline 1765 & y -cadinene & 1.53 & 0.55 & - \\
\hline 1794 & Nerol & - & - & 0.52 \\
\hline 1840 & Geraniol & - & - & 2.29 \\
\hline 1840 & Trans-calamenene & 1.46 & 0.55 & - \\
\hline 2009 & Caryophyllene oxide & 2.24 & - & 1.81 \\
\hline 2098 & Viridiflorol & 2.97 & 7.78 & - \\
\hline 2137 & Spathulenol & - & 0.64 & 3.39 \\
\hline 2164 & Farnesol & - & - & 0.62 \\
\hline 2179 & $\alpha$-cadinol & 2.87 & - & - \\
\hline 2181 & Sesquisabinene & - & - & 0.97 \\
\hline 2220 & $\alpha$-bisabolol & 7.32 & - & 0.84 \\
\hline 2242 & Tau-muurolol & 1.59 & - & - \\
\hline 2298 & Ar-curcumene & - & - & 2.07 \\
\hline 2365 & Sclareol & 2.89 & - & - \\
\hline 2655 & Phytol & 1.42 & - & - \\
\hline 2778 & 13-epi-manool & - & 18.14 & - \\
\hline \multicolumn{2}{|c|}{ Tanımlanan Bileșen \% } & 97.59 & 97.55 & 97.77 \\
\hline \multicolumn{2}{|c|}{ Tanımlanamayan Bileșen \% } & 2.41 & 2.45 & 2.23 \\
\hline
\end{tabular}


Bunun sebebinin çalışılan türün yetiştiği coğrafya ve ikliminden, farklı hasat zamanı, örneğin alındığı bitki kısmı (herba, yaprak, çiçek, sap) kurutma yöntemlerinden kaynaklanabileceği düşünülmektedir. Benzer şekilde; Özgüven ve ark., (2008)'a göre hasat zamanı, kurutma ve işleme, tıbbi bitkilerde sekonder metabolit içeriğini ve kompozisyonunu çok fazla etkilediği bildirilmiştir.

Çizelge 3. S. pilifera, S. tomentosa ve S. palaestina'nın sabit yağ asit bileşenleri

\begin{tabular}{|c|c|c|c|c|}
\hline \multirow[b]{2}{*}{ RT } & \multirow[b]{2}{*}{ Bileşenler } & \multicolumn{3}{|c|}{ Bileşen Oranı $(\%)$} \\
\hline & & S. pilifera & S. tomentosa & S. palaestina \\
\hline 4.625 & Caproic acid & - & 2.82 & - \\
\hline 10.992 & Capric acid & 8.6 & 11.72 & 25.17 \\
\hline 13.01 & Lauric acid & - & 3.09 & - \\
\hline 20.405 & Pentadecanoic acid & - & 3.59 & - \\
\hline 21.241 & Cis-10-pentadecanoic acid & - & - & 4.21 \\
\hline 22.102 & Palmitic acid & 18.07 & 7.49 & 11.03 \\
\hline 22.895 & Palmiteloic acid & - & 1.07 & - \\
\hline 24.373 & Heptadecanoic acid & - & 1.85 & - \\
\hline 26.643 & Stearic acid & 2.98 & 1.91 & - \\
\hline 27.321 & Oleic acid & 5.55 & 3.73 & 3.12 \\
\hline 29.037 & Linoleic acid & 9.13 & 5.57 & 7.84 \\
\hline 31.071 & $\mathrm{\gamma}$-linolenic acid & 36.37 & 15.81 & 11.55 \\
\hline 33.14 & Heneicosanoic acid & - & 1.59 & 35.10 \\
\hline 33.746 & Cis-11,14-eicosadienoic acid & - & 18.83 & - \\
\hline 35.141 & Behenic acid & 16.06 & 4.92 & - \\
\hline 37.142 & Tricosanoic acid & - & 1.01 & 1.95 \\
\hline 39.008 & Lignoceric acid & - & 5.74 & - \\
\hline 40.459 & Nervonic acid & - & 2.24 & - \\
\hline 42.656 & Cis-4,7,10,1,16,19- Docosahexaenoic acid & - & 6.94 & - \\
\hline \multicolumn{2}{|c|}{ Doymuş yağ oranı } & 45.71 & 45.73 & 77.46 \\
\hline \multicolumn{2}{|c|}{ Doymamış yağ oranı } & 51.05 & 54.19 & 22.51 \\
\hline
\end{tabular}

Tulukcu (2020), S. sclera L., nın farklı bitki kısımlarından elde edilen sabit yağ bileşenlerine bakıldığında; bitki kısımlarında major yağ asitleri olarak bilinen oleik asit, linoleik asit ve linolenik asit tespit edilmiş olup bu bileşenlerin yüzde oranları bitki kısımlarına göre değişiklik göstermiştir. S. sclarea çiçeklerinin, omega yağ asitlerinin en önemlisi olan $\alpha$-linolenik asit (C18:3) \% 29.37, oleik asitin (C18:1) \%10.01, linoleik asidin ise (C18:2) \%8.49 olduğu ve çiçekte bitkisel yağlarda bulunan en yaygın doymuş yağ asitlerinden olan palmitik asit (C16:0) \% 5.37 ve stearik asitin (C18:0) ise \% 11.37 rakamları arasında değiştiği, yapraklarında $\alpha$-linolenik asit \% 33.35, oleik asit \%5.89 ve linoleik asidin ise \% 5.78 değerleri arasında olduğu ve yaprakta palmitik asit \% 16.06, stearik asitin ise \% 6.48 aralığında değiştiği görülmüştür (Tulukcu, 2020).

\section{SONUÇ}

Bu çalışmada Kahramanmaraş florasında doğal olarak yayılış gösteren endemik $S$. pilifera ile $S$. tomentosa ve $S$. palaestina türlerinin toprak üstü kısımlarının uçucu ve sabit yağ bileşenleri belirlenmiştir. İncelenen üç Salvia türünün sabit ve uçucu yağlarında bileşen sayısı, bileşenlerin yüzde oranları ve başlıca bileşenler türden türe değişiklik göstermiş̧tir. Uçucu yağ bakımından; S. pilifera 'da başlıca bileşen \%20.43 ile $\alpha$-thujone iken, $S$. tomentosa'da \%19.32 ile $\alpha$-humulene ve $\% 18.14$ ile 13 -epi-manool, S. palaestina'da ise $\% 23.23$ linalyle acetate ve $\% 22.57$ ile $\beta$ caryophyllene olarak belirlenmiş̧ir. Uçucu yağ bileşenlerinden $\alpha$-thujone oranının S. pilifera ve S. tomentosa türlerinde yüksek olması bu türlerin kullanımı açısından önem arz etmektedir. Sabit yağ bakımından; S. pilifera' da başlıca bileşen $\% 36.37$ ile y-linolenic asit, $S$. tomentosa'da, \%18.83 ile cis-11,14-eicosadienoic asit ve S. palaestina'da $\% 35.10$ ile heneicosanoic asit olduğu görülmüştür. S. pilifera ve $S$. tomentosa'da doymamış yağ oranı doymuş yağ oranından yükssek iken, S. palaestina' da doymuş yağ oranı doymamış yağ oranından 3 kat daha yüksek olduğu görülmüştür.

\section{ÇIKAR ÇATIŞMASI}

Yazarlar bu yazı ile ilgili herhangi bir çıkar çatışması olmadığını beyan ederler. 


\section{YAZAR KATKISI}

Yazarlar makale üzerinde eşit katkı hakkına sahiptir.

\section{KAYNAKLAR}

Albayrak S, Aksoy A, Hamzaoğlu E 2008. Determination of antimicrobial and antioxidant activities of Turkish endemic Salvia halophila Hedge. Turk. J. Biol., 32: 265-270.

Al-Jaber HI, Al-Qudah MA, Barhoumi LM, Abaza IF, Afifi FU 2012. Essential oil composition of the aerial parts of fresh and air-dried Salvia palaestina Benth. (Lamiaceae) growing wild in Jordan. Natural Product Research, 26(13): 1179-1187.

Anonim 2012. https://www.bizimbitkiler.org.tr/v2/hiyerarsi.php?c=Salvia. (Erişim Tarihi: 14.09.2021)

Anonim 2020. Adaçayı Fizibilite Raporu ve Yatırıme Rehberi. T.C. Tarım ve Orman Bakanlığı Eğitim ve Yayın Dairesi Başkanlığı.

Anonim 2021. https://biruni.tuik.gov.tr/medas/?kn=92\&locale=tr.

Aşkun T, Başer KHC, Tumen G, Kürkcüoğlu M 2010. Characterization of essential oils of some Salvia species and their antimycobacterial activities. Turk J Biol., 34: 89-95.

Avcı AB 2013. Essential oil content and composition of Salvia tomentosa Mill. from Gölcük. Isparta. Suleyman Demirel University Journal of Natural and Applied Science 17(1): 1-4.

Baydar H 2005. Trbbi aromatik ve keyf bitkileri bilim ve teknolojisi, Süleyman Demirel Üniversitesi Ziraat Fakültesi Yayınları No: 51, Isparta, $125 \mathrm{~s}$.

Cantino PD, Harley RM, Wagstaff SJ 1992. Genera of Labiatae: Status and classification. In: Harley R., M., Reynolds T. (eds) Advances in Labiatae science. Royal Botanic Gardens, Kew. 511-522.

Celep F 2010. Revision of the genus Salvia L. (Labiatae) in the Mediterranean and the Aegean geographic regions of Turkey. PhD Thesis Middle East Technical University, Ankara, Turkey.

Ceylan A 1976. Salvia officinalis L. (Tıbbi Adaçayı) üzerinde bir çalışma. Ege Üniversitesi Ziraat Fakültesi Dergisi, 13: 283-288.

Davis PH (Ed.) 1982. Flora of Turkey and East Aegean Islands, Vol.7, Edinburgh, University Press, Edinburg.

Duman H, Byfield A 2000. Salvia albimaculata. Curtis's Botanical Magazine, 17 (2): 60-65.

Exarchou V, Kanetis L, Charalambous Z, Apers S, Pieters L, GekasV, Goulas V 2015. HPLC-SPE-NMR characterization of major metabolites in Salvia fruticosa Mill. extract with antifungal potential: relevance of carnosic acid, carnosol, and hispidulin Journal of Agricultural and Food Chemistry, 63(2): 457-463.

Güner A, Aslan S, Ekim T, Vural M, Babaç MT 2012. Türkiye bitkileri listesi (Damarlı Bitkiler). Nezahat Gökyiğit Botanik Bahçesi ve Flora Araştırmaları Derneği Yayını. İstanbul.

Gürsoy N, Tepe B, Akpulat A 2012. Chemical composition and antioxidant activity of the essential oils of Salvia palaestina (Bentham) and S. ceratophylla (L.), Rec. Nat. Prod. 6(3): 278-287.

Heywood V.H, Brummitt R.K, Seberg O, Culham A 2007. Flowering plant families of the World. Ontario, Firefly Books, Canada.

Kahraman A, Bagherpour S, Karabacak S, Doğan M, Doğan HM, Uysal İ, Celep F 2012. Reassessment of conservation status of Salvia L. (Lamiaceae) in Turkey II. Turk. J. Bot.,36: 103-124.

Kaya A, Dinç M, Doğu S, Demirci B 2017. Compositions of essential oils of Salvia adenophylla, Salvia pilifera, and Salvia viscosa in Turkey, Journal of Essential Oil Research, 29(3): 233-239.

Kelen M, Tepe B 2008. Chemical composition, antioxidant and antimicrobial properties of the essential oils of three Salvia species from Turkish flora, Biores. Technol., 99: 4096-4104.

Kintzios S (Ed.) 2000. Sage- The Genus Salvia-Medicinal and Aromatic Plant- Industrial profiles, Harwood Academic Publishers.

Kürkçüoğlu M, Duran A, Başer KHC 2019. The essentıal oils of four endemic Salvia species in Turkey. Chemistry of Natural Compounds, 55(2): 354-358.

Orhan İ, Şener B 2007. Antioxidant and anticholinesterase evaluation of selected Turkish Salvia species. Food Chemistry, 103:1247-1254.

Özgüven M, Sener B, Orhan I, Şekeroğlu N, Kirpik M, Kartal M 2008. Effects of varying nitrogen doses on yield: yield components and artemisinin content of Artemisia аппиа. Ind. Crops Prod. 27: 60-64.

Pavlidou V, Karpouhtsis I, Franzios G, Zambetaki A, Scouras Z, Mavraganitsipidou P 2004. Insecticidal and genotoxic effects of essentiial oils of Greek sage, Salvia fruticosa, and mint, Mentha pulegium, on Drosophila melanogaster and Bactrocera oleae (Diptera: Tephritidae). J. Agr. Urban. Entomol. 21(1): 39-49.

Sarrou E, Ganopoulos I, Xanthopoulou A, Masuero D, Martens S, Madesis P, Mavromatis A, Chatzopoulou P 2017. Genetic diversity and metabolic profile of Salvia officinalis populations: implications for advanced breeding strategies, Planta, 246(2): 201-215. 
Senatore F, Formisano C, Arnold N.A, Piozzi F 2005. Essential Oils from Salvia sp. (Lamiaceae). III. Composition and antimicrobial activity of the essential oil of Salvia palaestina Benth. growing wild in Lebanon, Journal of Essential Oil Research, 17(4): 419-421.

Şenel FS, Orhan I, Celep F, Kahraman A, Doğan M, Y1lmaz G, Şener B 2010. Survey of 55 Turkish Salvia taxa for their acetylcholinesterase inhibitory and antioxidant activities. Food Chemistry, 12: 34-43.

Sezik E, Ezer N 1983. Türkiye'de halk ilacı ve çay olarak kullanılan bitkiler üzerinde morfolojik ve anatomik araştırmalar. Doğa Bilim Dergisi, 7: 163-168.

Tulukcu E 2020. Salvia sclarea'nın bitki kısımlarının yă̆ asidi bileşenlerinin belirlenmesi. Avrupa Bilim ve Teknoloji Dergisi, 20: 957-960.

Uysal Bayar F, Çınar O 2020. Yield and quality parameters of some cultivated Origanum spp. species. Derim, 37(1): 1017.

Walker JB, Sytsma KJ 2007. Staminal evolution in the genus Salvia (Lamiaceae): molecular phylogenetic evidence for multiple origins of the staminal lever, Annals of Botany, 100(2): 375-391. 